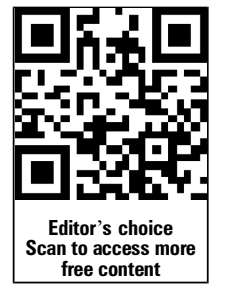

Department of Emergency Medicine, University of Colorado School of Medicine, Aurora, Colorado, USA

\section{Correspondence to}

Dr A A Ginde, Department of Emergency Medicine,

University of Colorado School of Medicine, $12401 \mathrm{E}$,

17th Avenue, B-215, Aurora, CO 80045, USA;

adit.ginde@ucdenver.edu

Received 21 January 2013 Revised 23 December 2013 Accepted 28 December 2013 Published Online First 28 January 2014

\section{SLinked}

- http://dx.doi.org/10.1136/ emermed-2014-203674

\title{
Frequent users of US emergency departments: characteristics and opportunities for intervention
}

\author{
Deborah T Vinton, Roberta Capp, Sean P Rooks, Jean T Abbott, Adit A Ginde
}

\section{ABSTRACT}

Objective To compare the characteristics of US adults by frequency of emergency department (ED) utilisation, specifically the prevalence of chronic diseases and outpatient primary care and mental health utilisation.

Methods We analysed 157818 adult participants of the 2004-2009 US National Health Interview Survey, an annual nationally representative sample. We defined ED utilisation during the past 12 months as non-users ( 0 ED visits), infrequent users (1-3 visits), frequent users (4-9 visits) and super-frequent users ( $\geq 10$ visits). We compared demographic data, socioeconomic status, chronic diseases and access to care between these ED utilisation groups using multivariable logistic regression. Results Overall, super-frequent use was reported by $0.4 \%$ of US adults, frequent use by $2 \%$ and infrequent ED use by $19 \%$. Patients reporting $\geq 4$ ED visits were more likely to have Medicaid insurance (OR 1.57; 95\% Cl 1.34 to 1.85 vs private); fair or poor self-reported health (OR 2.98; $95 \% \mathrm{Cl} 2.57$ to 3.46 vs excellent-very good); and chronic diseases such as coronary artery disease (OR 1.61; $95 \% \mathrm{Cl} 1.40$ to 1.86), stroke (OR $1.58 ; 95 \% \mathrm{Cl} 1.36$ to 1.83 ) or asthma (OR 1.64; $95 \%$ $\mathrm{Cl} 1.46$ to 1.85 ). While patients reporting the ED as their usual source of sick care were more likely to have $\geq 4$ ED visits (OR 7.09; $95 \% \mathrm{Cl} 5.61$ to 8.95 vs outpatient clinic as source), $\geq 10$ outpatient visits in the past 12 months was also associated with frequent ED use (OR 11.4; $95 \% \mathrm{Cl} 9.09$ to 14.2 vs no outpatient visits).

Conclusions Frequent ED users had a large burden of chronic diseases that also required high outpatient resources. Interventions designed to divert frequent ED users should focus on chronic disease management and access to outpatient services, particularly for Medicaid beneficiaries and other high risk subpopulations.

\section{INTRODUCTION}

US healthcare spending has nearly doubled over the past decade and is at an all time high, with nearly US\$8100 spent per capita annually. ${ }^{1}$ As healthcare costs continue to climb, policymakers and payers have become largely focused on the perceived high cost of emergency department (ED) care and a small number of frequent ED users who account for a disproportionate amount of healthcare costs. Often portrayed as impoverished, uninsured patients who visit the ED for 'inappropriate' reasons and 'unnecessarily' consume valuable healthcare resources, frequent ED users are blamed for ED crowding, increased wait times and escalating healthcare costs. ${ }^{2-5}$

Despite common assumptions that frequent ED use is a problem of patients who seek basic primary care in the ED, previous studies from several

\section{Key messages}

What is already known on this subject Previous studies make assumptions that frequent emergency department (ED) users access the ED for non-urgent conditions and for conditions that could be treated in the primary care provider's office. Although, a few studies show that frequent ED users have chronic diseases and utilize non-ED outpatient services frequently, those studies did not describe in detail the epidemiology of the chronic diseases and non-ED outpatient visits at the national level.

\section{What this study adds}

Our study suggests that frequent ED users have a significant burden of chronic diseases, such as coronary artery disease, stroke and asthma and are also high utilizers of non-ED outpatient resources. Interventions designed to decrease ED utilization should focus on chronic disease management and timely access to outpatient services, particularly for Medicaid beneficiaries.

different countries suggest that many frequent ED users have public or private insurance and have a greater burden of comorbid illness, higher admission rates and higher mortality. ${ }^{5-10}$ However, several previous studies were relatively small convenience samples from a few urban EDs, which limit the generalisability of results to other settings and geographic locations. The previous population based studies contained a relatively smaller number of observations, and used data from over a decade ago, which also limits the reliability and generalisability to the current population. ${ }^{6} 1112$ Prior analyses have identified frequent users only as those with $>4$ visits per year, and have not tried to further characterise super-frequent ED users as they compare to frequent and infrequent ED users. Finally, other analyses did not assess the prevalence of specific chronic diseases, and only described the prevalence of self-reported general health. More current, nationally representative, population based data on frequent and super-frequent ED utilisation would inform the development of effective interventions to improve access to healthcare and, when appropriate, curb frequent ED utilisation to reduce costs.

We sought to analyse US population based data to assess the association between patient characteristics and frequent ED ( $\geq 4$ ED visits/year) and super-frequent ( $\geq 10$ visits/year) ED users. We 
hypothesised that frequent ED users would have lower socioeconomic status and have a greater burden of chronic medical conditions, requiring higher ED and outpatient healthcare resources.

\section{METHODS}

\section{Study design}

We performed a secondary analysis on publicly available data from the US National Health Interview Survey (NHIS), conducted annually by the National Center for Health Statistics. The NHIS is an annual cross sectional household survey that approximates the non-institutionalised US civilian population. We received a waiver from our institutional review board to analyse data from the 2004-2009 NHIS.

\section{Study setting and population}

The NHIS collected household interview data from 2004 to 2009 from a total of 157818 adults (age $\geq 18$ years) who represent an annualised US population of 219 million. The specific details of the NHIS have been described elsewhere. ${ }^{13}$ In brief, the sample is obtained by using a stratified multi-stage probability study design with unequal probabilities of selection. Specific subgroups of peoples are purposefully oversampled by the NHIS, including racial/ethnic minorities. New households were surveyed each year, with each year's cohort selected to estimate health and healthcare characteristics of the entire US population. The annual response rate of NHIS is approximately $90 \%$ of the eligible households in the sample. Strategies for sampling and methodologies for data collection were very similar to maintain consistency and facilitate comparisons throughout the selected NHIS years.

\section{Data collection and measurements}

The NHIS queried the number of ED visits per year by the question, "During the past 12 months, how many times have you gone to a hospital emergency room (this includes emergency room visits that resulted in a hospital admission)?" (none, $1,2-3,4-5,6-7,8-9,10-12,13-15,16$ or more, don't know, refused). There is no commonly agreed upon definition of frequent ED use, with previous literature defining frequent utilisation as three visits annually to 12 or more visits annually. ${ }^{5} 8$ Based on available thresholds of the NHIS categorical data, we chose common definitions of frequent ED utilisation to define our study groups as non-users (0 visits/year), infrequent users (1-3 visits/year), frequent users (4-9 visits/year) and superfrequent users ( $\geq 10$ visits/year).

We compared demographic, socioeconomic status, health conditions and access to care among these ED utilisation groups. Demographic data included age, sex, marital status and race/ethnicity. Socioeconomic data included employment status, poverty-income ratio and education. Poverty income ratio was defined as per the NHIS as the ratio of family income to the poverty threshold for a family of that size. Self-reported health status was measured by response to the question, "Would you say your health in general is excellent, very good, good, fair or poor?" Cigarette and alcohol use were ascertained, but NHIS did not reliably measure other types of substance abuse. The survey asked about specific chronic health conditions (listed in table 2) based on the relatively high prevalence in the US adult population and potential for increased primary care and ED utilisation.

To ascertain what type of healthcare facility respondents most often visit for illnesses, participants were asked, "Is there a place that you usually go to when you are sick or need advice about your health?" and "What kind of place do you go to most often - a clinic, doctor's office, emergency room, hospital outpatient department or some other place?" For health insurance, we considered adults with private insurance (with or without any other types of health insurance) as 'private', and persons with Medicaid with or without Medicare as 'Medicaid \pm Medicare'. 'Medicare only' consisted only of those with Medicare but without private insurance or Medicaid. 'Other' insurance included adults who do not have private insurance, Medicaid or Medicare, but had other public or military health insurance. The number of outpatient and mental healthcare visits during the past 12 months were also extracted to compare ED utilisation with outpatient and mental health resource utilisation. Missing data were separately coded if prevalence of missingness was $\geq 2 \%$ (eg, for poverty-income ratio) and was dropped if $<2 \%$ of data were missing.

\section{Data analysis}

We performed statistical analyses using Stata V.10.1 (College Station, Texas, USA). Survey commands were used to adjust for the complex survey design and assign population sampling weights. The primary analysis was descriptive with 95\% CIs, comparing demographic and clinical characteristics by frequency of ED utilisation. We recognise that many selected variables are inter-related. We used logistic regression to evaluate the association between patient sociodemographic, clinical characteristics and number of ED visits. Two models were constructed, one with the outcome of interest being $\geq 4$ ED visits and the other with the outcome of interest being $\geq 10$ ED visits.

\section{RESULTS}

The demographic characteristics and socioeconomic status by frequency of ED utilisation are presented in table 1. Compared with non-ED users and infrequent ED users, frequent and superfrequent users were more frequently younger in age, female and racial/ethnic minorities, although absolute differences were relatively small. Lower rates of employment, lower poverty-income ratios (more impoverished) and less education achieved were also more frequently reported with higher ED utilisation.

Table 2 summarises the relationship between health conditions and access to healthcare by frequency of ED utilisation. Higher ED utilisation was associated with greater prevalence of chronic conditions such as hypertension $(44.6 \%$ vs $21.7 \%$ (ref $=0$ ED visits)), diabetes (22.3\% vs 6.8\% (ref=0 ED visits)), coronary artery disease $(19.7 \%$ vs $5.0 \%$ (ref=0 ED visits)), stroke $(11.1 \%$ vs $1.8 \%$ (ref $=0 \mathrm{ED}$ visits)), asthma $(22.7 \%$ vs $5.9 \%$ (ref $=0$ ED visits)) and emphysema (10.2\% vs $1.3 \%$ (ref $=0$ ED visits)). Although frequent and super-frequent ED users had higher rates of reporting never having smoked, they also had higher rates of being lifetime alcohol abstainers. Adults with higher ED utilisation reported ED as their preferred source of healthcare, suggesting a dependence on ED for healthcare. However, $80.3 \%$ of super-frequent ED users reported the outpatient clinic as their usual source of healthcare when sick, and $72.7 \%$ also reported $\geq 10$ outpatient visits during the past year. Furthermore, higher ED utilisation was also associated with higher outpatient and mental healthcare visits. The percentage of uninsured was similar across the four ED frequency groups; however, a higher proportion of frequent and super-frequent ED users were covered by Medicaid and a lower proportion were covered by private insurance.

Table 3 summarises the adjusted association between patient sociodemographic characteristics and frequent ED users $(\geq 4$ ED visits and $\geq 10$ ED visits). Characteristics associated with higher 
Table 1 Demographic characteristics of US National Health Interview Survey participants by emergency department visit frequency during the previous 12 months

\begin{tabular}{|c|c|c|c|c|}
\hline Characteristic & $\begin{array}{l}0 \text { ED visits ( } n=124433) \\
\%(95 \% \mathrm{Cl})\end{array}$ & $\begin{array}{l}\text { 1-3 ED visits ( } \mathrm{n}=29 \text { 971) } \\
\%(95 \% \mathrm{Cl})\end{array}$ & $\begin{array}{l}\text { 4-9 ED visits }(n=2803) \\
\%(95 \% \mathrm{Cl})\end{array}$ & $\begin{array}{l}\geq 10 \text { ED visits }(n=611) \\
\%(95 \% \mathrm{Cl})\end{array}$ \\
\hline \multicolumn{5}{|l|}{ Demographics } \\
\hline \multicolumn{5}{|l|}{ Age (years) } \\
\hline $18-44(n=74872)$ & 49.6 (49.1 to 50.2 ) & 50.9 (50.0 to 51.7$)$ & $52.6(50.2$ to 55.0$)$ & 54.6 (49.3 to 59.8$)$ \\
\hline $45-64(n=52161)$ & 34.8 (34.4 to 35.3$)$ & 30.0 (29.3 to 30.7$)$ & 29.7 (27.5 to 31.9$)$ & 27.8 (24.0 to 32.1$)$ \\
\hline$\geq 65(n=30785)$ & 15.5 (15.2 to 15.9$)$ & 19.2 (18.5 to 19.8$)$ & 17.7 (16.0 to 19.6$)$ & 17.6 (14 to 21.8$)$ \\
\hline Female sex $(n=88268)$ & 50.8 (50.4 to 51.1$)$ & 54.9 (54.1 to 55.6$)$ & $63.3(60.9$ to 65.6$)$ & $65.1(59.9$ to 70.0$)$ \\
\hline Married $(n=73361)$ & 58.1 (57.6 to 58.6$)$ & 49.9 (49.2 to 50.7$)$ & 41.3 (38.9 to 43.8$)$ & 44.1 (38.7 to 49.7$)$ \\
\hline \multicolumn{5}{|l|}{ Race/ethnicity } \\
\hline Non-Hispanic white ( $n=97$ 498) & 70.2 (69.7 to 70.8$)$ & $69.9(69.1$ to 70.7$)$ & 65.7 (63.2 to 68.2$)$ & $65.0(60.2$ to 69.6$)$ \\
\hline Non-Hispanic black ( $n=23$ 921) & $10.6(10.2$ to 11.0$)$ & 14.6 (14.0 to 15.3$)$ & 20.4 (18.4 to 22.5$)$ & 23.4 (19.4 to 27.8$)$ \\
\hline Hispanic ( $n=27986)$ & 13.6 (13.1 to 14.0$)$ & 11.7 (11.2 to 12.3$)$ & $11.4(10.0$ to 13.0$)$ & 9.3 (7.1 to 12.1$)$ \\
\hline Non-Hispanic Asian ( $n=7647)$ & 5.0 (4.8 to 5.2 ) & 3.0 (2.7 to 3.3$)$ & $1.7(1.2$ to 2.3$)$ & nc \\
\hline Other $(n=766)$ & $0.6(0.5$ to 0.7$)$ & $0.8(0.6$ to 1.0$)$ & $\mathrm{nc}$ & $\mathrm{nc}$ \\
\hline \multicolumn{5}{|l|}{ Socioeconomic status } \\
\hline Currently employed $(n=91390)$ & $63.1(62.7$ to 63.6$)$ & $52.5(51.8$ to 53.3$)$ & 32.4 (30.1 to 34.8$)$ & $23.0(19.1$ to 27.5$)$ \\
\hline \multicolumn{5}{|l|}{ Poverty-income ratio } \\
\hline$<1.0(n=20413)$ & 8.5 (8.1 to 8.8$)$ & 13.4 (12.9 to 14.0$)$ & 25.3 (23.4 to 27.4$)$ & $30.5(26.2$ to 35.1$)$ \\
\hline $1.0-1.9(n=25614)$ & 13.5 (13.3 to 13.8$)$ & 17.2 (16.6 to 17.7$)$ & 23.2 (21.3 to 25.2$)$ & 24.1 (19.9 to 28.7 ) \\
\hline $2.0-3.9(n=37706)$ & 24.6 (24.2 to 25.0$)$ & 25.4 (24.8 to 26.1$)$ & 21.6 (19.6 to 23.7 ) & 16.2 (12.9 to 20.2$)$ \\
\hline$\geq 4.0(n=44063)$ & 34.3 (33.7 to 34.8$)$ & 27.0 (26.2 to 27.7$)$ & 13.2 (11.5 to 15.1$)$ & $12.7(9.3$ to 17.1$)$ \\
\hline Unknown ( $\mathrm{n}=30$ 022) & 19.1 (18.7 to 19.6$)$ & 17.0 (16.4 to 17.6$)$ & $16.8(15.1$ to 18.6$)$ & 16.6 (13.5 to 20.2$)$ \\
\hline \multicolumn{5}{|l|}{ Education } \\
\hline$<$ High school ( $n=28812)$ & 14.8 (14.4 to 15.2$)$ & 19.5 (18.8 to 20.1$)$ & $29.2(27.2$ to 31.4$)$ & $31.3(27.0$ to 36.0$)$ \\
\hline High school graduate $(n=43760)$ & 28.3 (27.9 to 28.7 ) & 30.0 (29.3 to 30.8$)$ & 30.5 (27.9 to 33.2$)$ & $31.4(27.2$ to 35.6$)$ \\
\hline Some college ( $n=44869)$ & 29.0 (28.6 to 29.3 ) & 30.5 (29.8 to 31.3$)$ & 29.0 (26.9 to 31.2 ) & 27.0 (22.8 to 31.7$)$ \\
\hline$\geq$ Bachelors degree $(n=38954)$ & 28.0 (27.4 to 28.5$)$ & 20.0 (19.4 to 20.6$)$ & $11.3(9.9$ to 12.9$)$ & $10.3(7.5$ to 13.8$)$ \\
\hline
\end{tabular}

ED, emergency department; $n c$, not calculable due to $<30$ observations; ' $n$ ', represents number of observations in the National Health Interview Survey; percentages represented weighted proportions to estimate the entire US population.

ED use included: non-Hispanic race/ethnicity, Medicaid insurance, lower socioeconomic status, lower self-reported health status and several common chronic diseases. In addition, both patients reporting the ED as their usual source of sick care and those with $\geq 10$ outpatient visits in the past 12 months were more likely to report frequent ED use.

\section{DISCUSSION}

Accurate characterisation of frequent ED users is an important step in shaping solutions to reduce cost while increasing access to, and quality of care for, this complex population. In this national study of ED utilisation, we found that frequent and super-frequent ED users in the US had lower socioeconomic status, higher rates of Medicaid coverage and presence of debilitating chronic diseases (ie, hypertension, diabetes, stroke, emphysema). This likely explains why these patients also use the primary care clinics frequently, with $85 \%$ having four or more outpatient visits during the previous 12 months. These findings are consistent with previously published studies suggesting frequent and super-frequent ED users in the US, Canada and Europe have complex medical, social and psychiatric needs, and rely heavily on other parts of the healthcare system. ${ }^{6-8} 10$ 14-16 Here we expanded these findings to quantify the burden of chronic diseases for these patients and provided estimates that are representative of the entire US population. At this time we are unable to determine whether or not the reason for the ED visit is for an exacerbation of the patient's chronic disease, but it is possible that greater medication compliance and lifestyle modifications could improve these chronic conditions and reduce overall ED utilisation.

Challenging public perception that frequent ED users inappropriately consume ED resources, our results from the NHIS data suggest that frequent and super-frequent utilisers in the US have a perception of having poor general state of health. Unlike previous analyses, this study evaluated prevalence of specific chronic medical conditions among ED users. We were therefore not only able to demonstrate an association with selfreported poor health as previous studies have observed, but also document that frequent users do in fact have a higher rate of specific chronic medical conditions, such as emphysema, asthma, stroke and coronary artery disease. Additionally, frequent ED use was associated with outpatient mental health visits, indicating a higher prevalence of mental health conditions in this population.

Previous data from the USA suggests that adults with lower socioeconomic status, Medicaid insurance and comorbid illness had a higher rate of barriers to timely primary care access. ${ }^{17}$ Our results suggest that instead of abusing ED resources, many frequent and super-frequent users may visit the ED only when they are too sick to be seen in outpatient clinics, or when alternative sites of care cannot accommodate their needs within an adequate time frame. We were unable to assess for appropriateness of ED visits. However, given the aforementioned barriers to accessing primary care and other outpatient services, if these patients had the ability to access same day primary care appointments or improved access to 
Table 2 Health conditions and access to healthcare of US National Health Interview Survey participants by emergency department visit frequency during the previous 12 months

\begin{tabular}{|c|c|c|c|c|}
\hline Characteristic & $\begin{array}{l}0 \text { ED visits ( } n=124433) \\
\%(95 \% \mathrm{Cl})\end{array}$ & $\begin{array}{l}\text { 1-3 ED visits ( } \mathrm{n}=29 \text { 971) } \\
\%(95 \% \mathrm{Cl})\end{array}$ & $\begin{array}{l}\text { 4-9 ED visits }(n=2803) \\
\%(95 \% \text { Cl) }\end{array}$ & $\begin{array}{l}\geq 10 \text { ED visits }(\mathrm{n}=611) \\
\%(95 \% \mathrm{Cl})\end{array}$ \\
\hline \multicolumn{5}{|l|}{ Health conditions } \\
\hline \multicolumn{5}{|l|}{ Health status } \\
\hline Excellent-very good ( $n=92$ 125) & $65.0(64.6$ to 65.4$)$ & 48.4 (47.6 to 49.2$)$ & 25.4 (23.4 to 27.6$)$ & 19.4 (15.7 to 23.7$)$ \\
\hline Good ( $n=42839)$ & 25.4 (25.1 to 25.7 ) & 29.8 (29.2 to 30.1$)$ & 26.8 (24.7 to 29.0$)$ & 26.0 (21.4 to 31.3$)$ \\
\hline Fair-poor $(n=22769)$ & 9.6 (9.4 to 9.9$)$ & 21.7 (21.1 to 22.4$)$ & 47.8 (45.3 to 50.2$)$ & 54.6 (49.6 to 59.6$)$ \\
\hline Missing $(n=5700)$ & 3.6 (3.4 to 3.8$)$ & 2.9 (2.6 to 3.2$)$ & $2.9(2.2$ to 3.7$)$ & $\mathrm{nc}$ \\
\hline \multicolumn{5}{|l|}{ Body mass index $\left(\mathrm{kg} / \mathrm{m}^{2}\right)$} \\
\hline$<20(n=8803)$ & 5.7 (5.6 to 5.9$)$ & $5.8(5.5$ to 6.2$)$ & 7.0 (5.9 to 8.3 ) & $8.6(6.2$ to 11.8$)$ \\
\hline $20-24.9(n=49827)$ & 32.3 (31.9 to 32.6$)$ & $29.6(29.0$ to 30.3$)$ & 27.2 (24.9 to 29.6$)$ & 28.6 (24.1 to 33.6$)$ \\
\hline $25-29.9(n=53466)$ & 34.5 (34.2 to 34.8$)$ & 32.4 (31.7 to 33.0$)$ & 26.5 (24.4 to 28.8 ) & 24.6 (20.6 to 29.1$)$ \\
\hline$\geq 30(n=40022)$ & 23.9 (23.5 to 24.2$)$ & $29.3(28.7$ to 30.0$)$ & 36.4 (33.8 to 39.1$)$ & 34.3 (29.7 to 39.2$)$ \\
\hline Missing $(n=5700)$ & 3.6 (3.4 to 3.8 ) & 2.9 (2.6 to 3.2 ) & 2.9 (2.2 to 3.7$)$ & $\mathrm{nc}$ \\
\hline \multicolumn{5}{|l|}{ Alcohol use } \\
\hline Lifetime abstainer $(n=37$ 892) & $22.8 \%$ (22.3 to 23.2 ) & $21.4 \%$ (20.7 to 22.0$)$ & $25.4 \%$ (23.2 to 27.7$)$ & $28.7 \%$ (24.2 to 33.6$)$ \\
\hline Former $(n=23887)$ & $13.3 \%(13.0$ to 13.6$)$ & $17.8 \%(17.2$ to 18.4$)$ & $23.6 \%$ (21.5 to 25.7$)$ & $22.1 \%$ (18.4 to 26.4$)$ \\
\hline Current light ( $n=63333$ ) & $41.9 \%$ (41.5 to 42.3 ) & $40.4 \%$ (39.6 to 41.2 ) & $35.1 \%$ (32.6 to 37.8 ) & $37.1 \%$ (32.1 to 42.4 ) \\
\hline Current moderate/heavy ( $n=29041$ ) & $19.7 \%$ (19.3 to 20.1$)$ & $18.6 \%$ (18.0 to 19.2$)$ & $14.5 \%$ (12.8 to 16.4$)$ & $9.8 \%$ (7.2 to 13.3$)$ \\
\hline Missing $(n=3665)$ & $2.3 \%$ (2.2 to 2.5$)$ & $1.9 \%(1.7$ to 2.1$)$ & $1.4 \%(1.0$ to 2.0$)$ & $\mathrm{nc}$ \\
\hline \multicolumn{5}{|l|}{ Cigarette use } \\
\hline Never smoker $(n=91360)$ & $59.9(59.5$ to 60.3$)$ & 50.8 (50.0 to 51.6$)$ & $43.0(40.5$ to 45.6$)$ & 36.5 (32.4 to 40.8$)$ \\
\hline Current everyday ( $n=33$ 647) & 21.1 (20.8 to 21.5$)$ & 23.4 (22.8 to 24.0$)$ & $21.9(19.9$ to 24.1$)$ & 20.6 (16.6 to 25.2$)$ \\
\hline Former smoker $(n=31971)$ & $19.0(18.7$ to 19.3$)$ & 25.9 (25.1 to 26.6$)$ & 35.1 (32.7 to 37.6$)$ & $43.0(38.3$ to 47.8$)$ \\
\hline Hypertension $(n=40324)$ & 21.7 (21.4 to 22.0$)$ & 30.1 (29.5 to 30.8$)$ & 40.5 (38.3 to 42.7$)$ & 44.6 (39.9 to 49.4$)$ \\
\hline Diabetes $(n=13676)$ & $6.8(6.6$ to 7.0$)$ & $11.4(11.0$ to 11.9$)$ & 18.3 (16.4 to 20.4$)$ & 22.3 (18.7 to 26.4$)$ \\
\hline Coronary artery disease $(n=10930)$ & 5.0 (4.8 to 5.1$)$ & 10.9 (10.4 to 11.3$)$ & 19.9 (17.9 to 21.9$)$ & 19.7 (16.1 to 23.8$)$ \\
\hline Stroke $(n=4630)$ & $1.8(1.7$ to 1.9$)$ & $5.0(4.7$ to 5.3$)$ & $9.8(8.6$ to 11.0$)$ & $11.1(8.8$ to 14.0$)$ \\
\hline Asthma ( $n=11$ 639) & $5.9(5.7$ to 6.0$)$ & $11.5(11.0$ to 12.0$)$ & $22.2(20.2$ to 24.3$)$ & 22.7 (18.9 to 27.1$)$ \\
\hline Emphysema $(n=3023)$ & $1.3(1.2$ to 1.4$)$ & 3.3 (3.1 to 3.6 ) & 6.5 (5.5 to 7.6$)$ & $10.2(7.3$ to 14.1$)$ \\
\hline Cancer $(n=12268)$ & $6.8(6.7$ to 7.0$)$ & 9.7 (9.3 to 10.2$)$ & $13.6(12.1$ to 15.3$)$ & $12.5(9.8$ to 15.8$)$ \\
\hline \multicolumn{5}{|l|}{ Access to healthcare } \\
\hline \multicolumn{5}{|l|}{ Place usually go when sick } \\
\hline None $(n=24478)$ & $16.1(15.7$ to 16.5$)$ & 12.8 (12.3 to 13.4$)$ & $9.0(7.7$ to 10.5$)$ & 9.7 (7.0 to 13.3$)$ \\
\hline Emergency department ( $n=1606)$ & 0.5 (0.5 to 0.6$)$ & 2.2 (2.0 to 2.4$)$ & 5.5 (4.6 to 6.7$)$ & $10.0(7.2$ to 13.8$)$ \\
\hline Outpatient clinic ( $n=131$ 575) & $83.4(83.0$ to 83.8$)$ & $85.0(84.4$ to 85.6$)$ & 85.5 (83.7 to 87.1$)$ & 80.3 (75.9 to 84.1$)$ \\
\hline \multicolumn{5}{|l|}{ Health insurance } \\
\hline Any private $(\mathrm{n}=98 \mathrm{705})$ & $69.2(68.7$ to 69.6$)$ & 60.1 (59.3 to 60.9$)$ & 39.7 (37.2 to 42.3$)$ & $34.0(29.5$ to 38.8$)$ \\
\hline Medicaid $( \pm$ Medicare) $(n=13426)$ & 5.1 (4.9 to 5.3$)$ & $11.5(11.0$ to 12.0$)$ & 26.4 (24.3 to 28.5$)$ & 33.9 (29.5 to 38.7$)$ \\
\hline Medicare only $(n=12736)$ & $6.2(6.0$ to 6.4$)$ & $8.5(8.1$ to 9.0$)$ & $10.6(9.3$ to 12.0$)$ & $9.4(7.2$ to 12.1$)$ \\
\hline Other $(n=4893)$ & $2.6(2.4$ to 2.7$)$ & 3.6 (3.4 to 3.9$)$ & 5.1 (3.9 to 6.5$)$ & 5.2 (3.6 to 7.4$)$ \\
\hline Not covered $(n=27552)$ & $17.0(16.7$ to 17.3$)$ & $16.3(15.7$ to 16.9$)$ & $18.3(16.5$ to 20.4$)$ & $17.6(14.0$ to 21.8$)$ \\
\hline \multicolumn{5}{|l|}{ No of outpatient visits in past 12 months } \\
\hline None $(n=30227)$ & 22.4 (22.0 to 22.7$)$ & 8.1 (7.7 to 8.6$)$ & 5.5 (4.5 to 6.7$)$ & 6.6 (4.5 to 9.4$)$ \\
\hline $1-3(n=65316)$ & $45.4(45.0$ to 45.8$)$ & 35.8 (35.0 to 36.6$)$ & $12.0(10.5$ to 13.7$)$ & 7.0 (4.6 to 10.6$)$ \\
\hline $4-9(n=38345)$ & $22.0(21.7$ to 22.3$)$ & 30.9 (30.2 to 31.6$)$ & $34.8(32.5$ to 37.0$)$ & 13.7 (10.8 to 17.2$)$ \\
\hline$\geq 10(n=22735)$ & $10.2(10.0$ to 10.5$)$ & 25.2 (24.5 to 25.8$)$ & $47.8(45.6$ to 50.0$)$ & 72.7 (68.1 to 77.0$)$ \\
\hline Mental healthcare in past 12 months $(n=11350)$ & 5.5 (5.3 to 5.6$)$ & $11.6(11.1$ to 12.1$)$ & 21.9 (20.0 to 23.8$)$ & 26.7 (23.0 to 30.8 ) \\
\hline
\end{tabular}

other subspecialty services, the number of ED visits could decrease. Furthermore, programmes involving patient navigators have shown improvements in the management of chronic diseases, such as diabetes, hypertension and congestive heart failure. ${ }^{18} 19$ These types of programmes could help patients manage their chronic illnesses and potentially avoid ED visits and future hospitalisations.

\section{Limitations}

Our study has several potential limitations. Although the NHIS sampling method was designed to include a nationally representative sample of US residents, it did not survey the homeless population, nursing homes, prisons or mental health facilities. We know from previously published data that these adults tend to have frequent ED utilisation. ${ }^{20}$ Thus our results may not be 
Table 3 Adjusted association between participant characteristics and frequent or super-frequent emergency department use during the previous 12 months

\begin{tabular}{|c|c|c|}
\hline Characteristic & $\begin{array}{l}\geq 4 \text { ED visits } \\
\text { OR }(95 \% \mathrm{Cl})\end{array}$ & $\begin{array}{l}\geq 10 \text { ED visits } \\
\text { OR }(95 \% \mathrm{Cl})\end{array}$ \\
\hline \multicolumn{3}{|l|}{ Demographics } \\
\hline \multicolumn{3}{|l|}{ Age (years) } \\
\hline $18-44$ & Ref & Ref \\
\hline $45-64$ & 0.43 (0.38 to 0.49 ) & $0.39(0.30$ to 0.51$)$ \\
\hline$\geq 65$ & $0.32(0.26$ to 0.38$)$ & $0.36(0.24$ to 0.53$)$ \\
\hline Female sex & 1.14 (1.02 to 1.27$)$ & 1.12 (0.87 to 1.43$)$ \\
\hline Married & 0.92 (0.83 to 1.03$)$ & 1.21 (0.94 to 1.57 ) \\
\hline \multicolumn{3}{|l|}{ Race/ethnicity } \\
\hline Non-Hispanic white & Ref & Ref \\
\hline Non-Hispanic black & 1.44 (1.27 to 1.64$)$ & 1.67 (1.30 to 2.13$)$ \\
\hline Hispanic & 0.75 (0.64 to 0.89 ) & 0.70 (0.50 to 0.98$)$ \\
\hline Non-Hispanic Asian & $0.53(0.39$ to 0.73$)$ & $\mathrm{nc}$ \\
\hline Other & $0.96(0.57$ to 1.61$)$ & $\mathrm{nc}$ \\
\hline \multicolumn{3}{|l|}{ Socioeconomic status } \\
\hline Currently employed & $0.71(0.63$ to 0.80$)$ & 0.57 (0.42 to 0.77$)$ \\
\hline \multicolumn{3}{|l|}{ Poverty-income ratio } \\
\hline$<1.0$ & 1.81 (1.49 to 2.20$)$ & 1.61 (1.04 to 2.50$)$ \\
\hline $1.0-1.9$ & 1.70 (1.42 to 2.04$)$ & 1.49 (0.96 to 2.32 ) \\
\hline $2.0-3.9$ & 1.38 (1.15 to 1.64$)$ & 1.01 (0.65 to 1.56$)$ \\
\hline$\geq 4.0$ & Ref & Ref \\
\hline Unknown & 1.39 (1.16 to 1.67$)$ & 1.17 (0.77 to 1.79$)$ \\
\hline \multicolumn{3}{|l|}{ Education } \\
\hline$<$ High school & 1.54 (1.29 to 1.84$)$ & 1.41 (0.90 to 2.19$)$ \\
\hline High school graduate & 1.25 (1.04 to 1.50$)$ & 1.15 (0.77 to 1.71$)$ \\
\hline Some college & 1.30 (1.10 to 1.53$)$ & 1.20 (0.79 to 1.82 ) \\
\hline$\geq$ Bachelors degree & Ref & Ref \\
\hline \multicolumn{3}{|l|}{ Health conditions } \\
\hline \multicolumn{3}{|l|}{ Health status } \\
\hline Excellent-very good & Ref & Ref \\
\hline Good & 1.61 (1.40 to 1.86$)$ & 1.80 (1.25 to 2.60$)$ \\
\hline Fair-poor & 2.98 (2.57 to 3.46$)$ & $2.90(2.00$ to 4.20$)$ \\
\hline Missing & 3.27 (1.06 to 10.11$)$ & $\mathrm{nc}$ \\
\hline \multicolumn{3}{|l|}{ Body mass index $\left(\mathrm{kg} / \mathrm{m}^{2}\right)$} \\
\hline$<20$ & 1.13 (0.93 to 1.38$)$ & 1.18 (0.80 to 1.75$)$ \\
\hline $20-24.9$ & Ref & Ref \\
\hline $25-29.9$ & 0.85 (0.74 to 0.97$)$ & 0.72 (0.54 to 0.97$)$ \\
\hline$\geq 30$ & $0.90(0.78$ to 1.05$)$ & 0.71 (0.53 to 0.95$)$ \\
\hline Missing & 0.85 (0.66 to 1.09$)$ & $\mathrm{nc}$ \\
\hline \multicolumn{3}{|l|}{ Alcohol use } \\
\hline Lifetime abstainer & Ref & Ref \\
\hline Former & 0.90 (0.77 to 1.05$)$ & 0.66 (0.47 to 0.90$)$ \\
\hline Current light & 0.95 (0.82 to 1.10$)$ & 0.89 (0.67 to 1.19$)$ \\
\hline Current moderate/heavy & 0.94 (0.77 to 1.14$)$ & 0.61 (0.40 to 0.95$)$ \\
\hline Missing & 0.69 (0.47 to 1.02$)$ & $\mathrm{nc}$ \\
\hline \multicolumn{3}{|l|}{ Cigarette use } \\
\hline Never smoker & Ref & Ref \\
\hline Current everyday & $1.10(0.95$ to 1.27$)$ & 1.22 (0.90 to 1.66$)$ \\
\hline Former smoker & $1.51(1.34$ to 1.70$)$ & 1.93 (1.53 to 2.42$)$ \\
\hline Hypertension & 1.11 (0.98 to 1.25$)$ & 1.21 (0.94 to 1.55$)$ \\
\hline Diabetes & 1.15 (1.00 to 1.32$)$ & 1.39 (1.06 to 1.83$)$ \\
\hline Coronary artery disease & 1.61 (1.40 to 1.86$)$ & $1.27(0.94$ to 1.70$)$ \\
\hline Stroke & 1.58 (1.36 to 1.83$)$ & 1.43 (1.06 to 1.94$)$ \\
\hline Asthma & 1.64 (1.46 to 1.85$)$ & 1.31 (1.01 to 1.71$)$ \\
\hline Emphysema & 1.19 (0.96 to 1.47$)$ & 1.81 (1.19 to 2.76$)$ \\
\hline Cancer & 1.19 (1.03 to 1.38$)$ & 0.98 (0.71 to 1.35$)$ \\
\hline
\end{tabular}


Table 3 Continued

\begin{tabular}{|c|c|c|}
\hline Characteristic & $\begin{array}{l}\geq 4 \text { ED visits } \\
\text { OR }(95 \% \mathrm{Cl})\end{array}$ & $\begin{array}{l}\geq 10 \text { ED visits } \\
\text { OR }(95 \% \mathrm{CI})\end{array}$ \\
\hline \multicolumn{3}{|l|}{ Access to healthcare } \\
\hline \multicolumn{3}{|l|}{ Place usually go when sick } \\
\hline None & $1.07(0.90$ to 1.27$)$ & $1.41(0.96$ to 2.09$)$ \\
\hline Emergency department & 7.09 (5.61 to 8.95$)$ & 9.22 (5.88 to 14.4$)$ \\
\hline Outpatient clinic & Ref & Ref \\
\hline \multicolumn{3}{|l|}{ Health insurance } \\
\hline Any private & Ref & Ref \\
\hline Medicaid ( \pm Medicare) & 1.57 (1.34 to 1.85$)$ & 1.61 (1.15 to 2.24$)$ \\
\hline Medicare only & 1.14 (0.95 to 1.38$)$ & $1.03(0.68$ to 1.56$)$ \\
\hline Other & $1.54(1.18$ to 2.02$)$ & 1.50 (0.96 to 2.36$)$ \\
\hline Not covered & $1.54(1.31$ to 1.80$)$ & $1.40(0.97$ to 2.03$)$ \\
\hline \multicolumn{3}{|l|}{ No of outpatient visits in past 12 months } \\
\hline None & Ref & Ref \\
\hline $1-3$ & $1.29(1.00$ to 1.64$)$ & $0.74(0.40$ to 1.37$)$ \\
\hline $4-9$ & $5.52(4.42$ to 6.90$)$ & 2.11 (1.27 to 3.50$)$ \\
\hline$\geq 10$ & 11.4 (9.09 to 14.2$)$ & 13.0 (7.98 to 21.2$)$ \\
\hline Mental healthcare in past 12 months & $1.37(1.21$ to 1.54$)$ & 1.36 (1.07 to 1.73$)$ \\
\hline
\end{tabular}

entirely generalisable to all ED users, and may underestimate the prevalence of mental illness, substance abuse and distribution of socioeconomic status among frequent users. For example, although previous studies reported a high prevalence of alcohol and drug abuse among frequent users, 7101520 we found that frequent ED users in NHIS did not have a higher prevalence of alcohol or tobacco abuse. However, demographic characteristics from this sample were similar to those from US ED utilisation data. ${ }^{21}$

The NHIS information is based on self-reported responses, so ED utilisation could not be confirmed and is subject to lack of response and recall bias. Additionally, similar to other survey datasets, our findings were limited by our inability to construct additional survey questions, such as incidence of recreational drug use and reasons for each visit to the ED and outpatient clinics. We were also unable to gather information on hospital admission or length of hospital stay, limiting our ability to draw any conclusions about the severity of illness. Reported associations may not be causally related and may be confounded by variables included in the analysis or unmeasured factors not included in the NHIS.

\section{CONCLUSIONS}

In conclusion, our results suggest that frequent and superfrequent ED users in the US are a vulnerable group of individuals with Medicaid insurance, of lower socioeconomic status and with significant chronic medical and mental health conditions. In an attempt to reduce healthcare costs, several interventions have been designed and implemented to divert frequent users from the ED to primary care services. In our study, we were unable to evaluate whether or not the ED visits made by these groups of patients were appropriate or inappropriate, although our data suggest that these patients have an established primary care provider (as illustrated by the high number of outpatient visits) and health insurance. Given previous studies suggesting patients with Medicaid face significant barriers in accessing primary care services in a timely fashion, we believe that interventions aimed at improving overall individual health and increasing access to primary care services, including same day appointments during acute illnesses, may prove more effective in reducing the frequency of ED visits in the USA. Future interventions, such as patient navigation, that account for individual level factors may be more effective at reducing frequent ED utilisation.

Contributors DTV conceived and designed the study, interpreted the data and drafted the manuscript. RC interpreted the data and revised the manuscript. SPR performed the data analysis and revised the manuscript. JTA interpreted the data and revised the manuscript. AAG conceived and designed the study, performed the data analysis, interpreted the data and revised the manuscript. AAG takes responsibility for the paper as a whole. All authors approved the final version of the manuscript to be published.

\section{Competing interests None.}

Ethics approval The study was approved by the Colorado Multiple Institutional Review Board.

Provenance and peer review Not commissioned; externally peer reviewed.

\section{REFERENCES}

1 Schoenman J, Chockley N. NIHCM Foundation analysis of data from the 2011 Medical Expenditure Panel Survey. http://meps.ahrq.gov/mepsweb (accessed 13 Jan 2012).

2 Arroliga A, Griswold S. "Frequent fliers" do not receive a free trip in the emergency department. Chest 2005;128:4051-2.

3 Malone RE. Almost "like family": emergency nurses and "frequent flyers". J Emerg Nurs 1996;22:176-83.

4 Althaus F, Paroz S, Hugli 0, et al. Effectiveness of interventions targeting frequent users of emergency departments: a systematic review. Ann Emerg Med 2011:58:41-52.

5 LaCalle $E$, Rabin E. Frequent users of emergency departments: the myths, the data, and the policy implications. Ann Emerg Med 2010;56:42-8.

6 Hunt KA, Weber EJ, Showstack JA, et al. Characteristics of frequent users of emergency departments. Ann Emerg Med 2006;48:1-8.

7 Doupe MB, Palatnick W, Day $S$, et al. Frequent users of emergency departments: developing standard definitions and defining prominent risk factors. Ann Emerg Med 2012;60:24-32.

8 Locker T, Baston S, Mason S, et al. Defining frequent use of an urban emergency department. Emerg Med J 2007:24:398-401. 
9 Hansagi $\mathrm{H}$, Olsson $\mathrm{M}$, Sjoberg $\mathrm{S}$, et al. Frequent use of the hospital emergency department is indicative of high use of other health care services. Ann Emerg Med 2001;37:561-7.

10 Smits F, Brouwer $H$, Riet $G$, et al. Epidemioloy of frequent attenders: a 3-year historic cohort study comparing attendance, morbidity and prescriptions of one-year and persistent frequent attenders. Emerg Med J 2007;24:398-401.

11 Weber EJ, Showstack JA, Hunt KA, et al. Does lack of a usual source of care or health insurance increase the likelihood of an emergency department visit? Results of a national population-based study. Ann Emerg Med 2005;45:4-12.

12 Fuda KK, Immekus R. Frequent users of Massachusetts emergency departments: a statewide analysis. Ann Emerg Med 2006;48:9-16.

13 Centers for Disease Control and Prevention. Summary health statistics for the US population: National Health Interview Survey 2009. http://www.cdc.gov/nchs/data/ series/sr 10/sr10 249.pdf (accessed 13 Jan 2012).

14 Byrne $M$, Murphy $A$, Plunkett $P$, et al. Frequent attenders to an emergency department: A study of primary health care use, medical profile, and psychosocial characteristics. Ann Emerg Med 2003;41:309-18.
15 Capp R, Rosenthal MS, Desai MM, et al. Characteristics of Medicaid enrollees with frequent ED use. Am J Emerg Med 2013;31:1333-7.

16 Bieler G, Paroz S, Faouzi M, et al. Social and medical vulnerability factors of emergency department frequent users in a universal health insurance system. Acad Emerg Med 2012;19:63-8.

17 Cheung PT, Wiler JL, Ginde AA. Changes in barriers to primary care and emergency department utilization. Arch Intern Med 2011;171:1397-9.

18 Esperat MC, Flores D, McMurry L, et al. Transformacion para salud: a patient navigation model for chronic disease self-management. Online J Issues Nurs 2012;17:2.

19 Lorig KR, Sobel DS, Ritter PL, et al. Effect of a self-management program on patients with chronic disease. Eff Clin Pract 001;(6):256-62.

20 Kushel MB, Perry S, Bangsberg D, et al. Emergency department use among the homeless and marginally housed: results from a community-based study. Am J Public Health 2002:92:778-84.

21 Centers for Disease Control and Prevention. National Hospital Ambulatory Medical Care Survey: 2009 Emergency Department Summary Tables. http://www.cdc.gov/nchs/data/ ahcd/nhamcs_emergency/2009_ed_web_tables.pdf (accessed 28 Jun 2013). 